\title{
Application of the FASTHUG-MAIDENS mnemonic and evaluation of its impact on a pharmaceutical intervention in an intensive care unit for adults
}

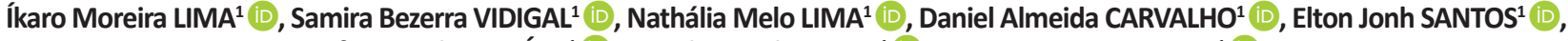 \\ Afonso Celso JUNíOR ${ }^{1}$ (i), Leandra Marla VIANA ${ }^{1}$ (D), lara Antonia NOGUEIRA ${ }^{1}$ (i) \\ ${ }^{1}$ Hospital Universitário da Universidade Federal do Maranhão \\ Corresponding author: Lima IM, ikarofarma@gmail.com
}

Submitted: 21-01-2021 Resubmitted: 07-03-2021 Accepted: 07-03-202

Peer review: blind reviewer and Aline Lins Camargo

\begin{abstract}
Objective: To evaluate the impact of the application of the FASTHUG-MAIDENS mnemonic by clinical pharmacists to optimize critically ill patients' pharmacotherapy. Methods: Cross-sectional study performed on an adult intensive care unit of an University Hospital, between august and november 2019, where 155 patients were followed by three clinical pharmacists during hospital stay. Patients who stayed less than 24 hours in the hospital or whose stay was during weekends or holidays were excluded. The interventions were performed together with a multidisciplinary team using FASTHUG-MAIDENS, as well as technical analysis of medical prescription and patients' clinical evaluation. The clinical evaluation included analysis of laboratory tests, nursing records and medical prescription, all registered in an institutional spreadsheet. The pharmaceutical interventions were registered in the pharmaceutical section of both physic and electronic medical records, and the data were later evaluated, classified, and submitted to descriptive analytical analysis. Results: 1.145 pharmaceutical interventions were performed, with an acceptance rate of $99,3 \%$. The number of pharmaceutical interventions were increased by $104,4 \%$ with the application of the FASTHUG-MAIDENS mnemonic, compared to the period before the research. The main interventions performed were: inclusion of a drug (25,2\%), exclusion of a drug (17,9\%), dose adjustment $(12,2 \%)$, change of the administration timetable to avoid intravenous incompatibility $(11,4 \%)$, inclusion of infusion rate $(7,3 \%)$, dilution adequacy $(5,8 \%)$, inclusion of reconstitution (3,5\%), microbiological culture request $(3,4 \%)$, drug interaction monitoring $(2,7 \%)$, adequacy of infusion rate (2,6\%) and others (7,4\%).Pharmaceutical interventions showed clinical (96,9\%), preventive (99,3\%) and economic (21,6\%) impact. Conclusion: The application of the FASTHUG-MAIDENS mnemonic extended the pharmaceutical care to critically ill patients, enabling an accurate evaluation of the pharmacotherapy, clinically impacting critical patient care and reducing errors and adverse drug events.
\end{abstract}

Keywords: pharmaceutical services; critical care; pharmacists; patient safety; drug-related side effects and adverse reactions; pharmacy service, hospital.

\section{Aplicação do mnemônico FASTHUG-MAIDENS e avaliação do seu impacto nas intervenções farmacêuticas em unidade de cuidados intensivos adulto}

\section{Resumo}

Objetivo: Avaliar o impacto da aplicação do mnemônico FASTHUG-MAIDENS por farmacêuticos clínicos na otimização da farmacoterapia em pacientes críticos. Métodos: Estudo transversal realizado na unidade de cuidados intensivos adulto de um hospital universitário, no período de agosto a novembro de 2019, onde foram acompanhados 155 pacientes por três farmacêuticos clínicos, durante internação hospitalar. Não foram incluídos pacientes com internação inferior a $24 \mathrm{~h}$ e durante os finais de semana e feriados. As intervenções farmacêuticas foram efetivadas em conjunto com a equipe multidisciplinar a partir da aplicação do FASTHUG-MAIDENS, análise técnica da prescrição médica e avaliação clínica dos pacientes. A avaliação clínica baseou-se nos exames laboratoriais, balanço de enfermagem e prescrição médica, sendo os dados registrados em planilha institucional. As intervenções farmacêuticas foram registradas na evolução farmacêutica no prontuário físico e eletrônico, e, posteriormente, os dados foram avaliados e classificados e submetidos a análise estatística descritiva. Resultados: Foram realizadas 1.145 intervenções farmacêuticas, com taxa de aceitação das intervenções de 99,3\%. A aplicação do mnemônico FASTHUG-MAIDENS aumentou em 104,4\% o número de intervenções farmacêuticas realizadas, comparado com o período anterior a pesquisa. As principais intervenções farmacêuticas foram inclusão de um medicamento (25,2\%), exclusão de um medicamento $(17,9 \%)$, ajuste de dose (12,2\%), orientação de aprazamento devido incompatibilidade medicamentosa (11,4\%), inclusão de velocidade de infusão (7,3\%), adequação de diluição $(5,8 \%)$, inclusão de reconstituição $(3,5 \%)$, solicitação de culturas $(3,4 \%)$, monitoramento de interação medicamentosa $(2,7 \%)$, adequação de velocidade de infusão $(2,6 \%)$ e outros $(7,4 \%)$. As intervenções farmacêuticas realizadas tiveram impacto clínico $(96,9 \%)$, preventivo $(99,3 \%)$ e econômico $(21,6 \%)$. Conclusão: A aplicação do mnemônico FASTHUG-MAIDENS ampliou o cuidado farmacêutico ao paciente crítico, possibilitando avaliação de pontos essenciais da farmacoterapia, impactando clinicamente o cuidado ao paciente crítico, reduzindo erros e eventos adversos relacionados a medicamentos.

Palavras-chave: assistência farmacêutica; cuidados críticos; farmacêuticos; segurança do paciente, efeitos colaterais e reações adversas relacionados a medicamentos; serviço de farmácia hospitalar. 


\section{Introduction}

Resolution 585/2013 of the Federal Pharmacy Council defines that the clinical attributions of the pharmacist aim at health promotion, protection and recovery, in addition to the prevention of diseases and other health problems at all health care levels. ${ }^{1}$ The pharmacists working in intensive care are specialists in pharmacotherapy and contribute positively to the care of critically-ill patients, focusing on the clinical assessment and pharmacotherapy of the patients, intervening in the management of antimicrobials, vasoactive drugs, electrolytes, neuromuscular blockers, sedation and analgesia, in addition to the analysis and provision of safe, efficient and rational pharmacotherapy, contributing to a reduction in medication costs. ${ }^{2}$ Resolution 675/2019 regulates the attributions of the clinical pharmacists in intensive care units and defines as one of their duties to analyze the patient's prescription regarding the legal and technical aspects, so as to promote the adequate use of medications, nutrients and other health products. ${ }^{3}$

The inclusion of pharmacist specialized in critical care in an intensive care unit results in an increase in the number of pharmaceutical interventions in comparison to a non-specialized pharmaceutical service, improving the quality of the assistance provided to the patient. ${ }^{4}$ However, there is no standardized and structured approach to assist pharmacists in intensive care units, which can cause delay in the identification of Drug-Related Problems (DRPs) and therapy optimization. ${ }^{5}$

The FASTHUG mnemonic was developed by intensive care physicians with the aim of ensuring that important aspects of care are addressed in the daily assessment of the patient. ${ }^{6}$ However, there are no aspects in this mnemonic that specifically evaluate pharmacotherapy, being then modified to FASTHUG-

MAIDENS. ${ }^{6}$ FASTHUG-MAIDENS assesses diet, analgesia, sedation, thromboembolism prophylaxis, delirium, stress ulcer prophylaxis, glycemic control, medication reconciliation, antimicrobials, medication indication, medication dose, electrolytes, hematology and laboratory tests, absence of drug interactions, allergies, duplicates or adverse reactions and stop dates, and can assist clinical pharmacists who work in intensive care as a daily checklist for patient evaluation, to guide clinical pharmacists without experience in intensive care, and as a learning tool for residents and interns. ${ }^{5}$

The use of the FASTHUG-MAIDENS tool in conjunction with pharmaceutical interventions can increase ventilator-free time, decrease the time for empirical antibiotic therapy, reduce the duration of central venous catheters, and increase rates of adherence to therapies for the prevention of deep venous thrombosis and prophylaxis for stress ulcers. ${ }^{7}$ In addition, it is necessary to ensure open communication between clinical pharmacists and the medical team regarding guidance for the selection, evaluation and monitoring of pharmacotherapy, in order to support the description or reduction of the use of drugs for clinical conditions without strong indications and based on evidence, thus promoting safety and cost reduction in health institutions. ${ }^{8}$

Thus, this study aims to assess the impact of the FASTHUGMAIDENS mnemonic in pharmaceutical interventions in criticallyill adult patients, using it as a daily clinical checklist to optimize the pharmacotherapy of patients admitted to the Clinical Intensive Care Unit for Adults (Unidade de Cuidados Intensivos Clínico Adulto, UCICA) of the University Hospital of the Federal University of Maranhão (Hospital Universitário-Universidade Federal do Maranhão, HU-UFMA).

\section{Methods}

This is a cross-sectional study conducted in the period from August to November 2019 in the UCICA/HU-UFMA by clinical pharmacists. The UCICA/HU-UFMA consists of 10 beds, where mainly surgical patients are served, in addition to clinical patients admitted to the HU-UFMA.

For sample calculation, the number of patients hospitalized $(n=195)$ at UCICA/HU-UFMA between February and May 2019 was considered, sampling error of 5\%, 95\% confidence level, and a proportion of DRPs in the population of $62 \%$, with a sample of 127 patients estimated. The inclusion criteria were all the patients (clinical and surgical) monitored by clinical pharmacists during the research period. The exclusion criteria were patients with a hospital stay of less than 24 hours and during weekends and holidays, as there was no clinical pharmacy service in these hours.

For daily data collection, a physical spreadsheet was used for each patient, elaborated by the clinical pharmacy unit of HU-UFMA. The clinical evaluation of each patient was carried out by three clinical pharmacists (two specialists in clinical pharmacy and an intensive care resident), on working days, during the morning and afternoon periods, which was based on the analysis and monitoring of vital signs and 24-hour controls (temperature, blood pressure, heart rate, respiratory rate, blood glucose, oxygen saturation, pain, diuresis, gastric waste, vomiting, evacuation, use of blood components and flow of drains and ostomies), in addition to analysis of laboratory tests (complete blood count, biochemistry, coagulogram and blood gas analysis). After collecting the clinical data, the clinical pharmacists applied FASTHUG-MAIDENS and performed a pharmaceutical evaluation of the electronic medical prescriptions, the following being analyzed, respectively: $F=$ Feeding, $A=$ Analgesia, $\mathrm{S}=$ Sedation, $\mathrm{T}=$ Thromboembolic prophylaxis, $\mathrm{H}=$ Hypoactive or hyperactive delirium, $U$ = Stress ulcer prophylaxis, $G=$ Glucose control, $M=$ Medication reconciliation (depending on the patients' clinical and hemodynamic status), $\mathrm{A}=$ Antimicrobials, I = Indication of the medications, $\mathrm{D}=$ Dose of the medications, $\mathrm{E}=$ Electrolytes, hematology and other laboratory tests, $\mathrm{N}=$ No drug interactions, allergies, duplications and adverse reactions and $S=$ Stop dates, in addition to the absence, presence or adequacy of the reconstitution, dilution, infusion time and scheduling of the prescribed medications. Figure 1 systematizes the work process conducted daily by the clinical pharmacists on each patient. The identification of the drug interactions and incompatibilities was performed by means of the Micromedex ${ }^{\circ}$ database. The pharmaceutical interventions were made in person as suggestions, during the medical prescription process and round with a multidisciplinary team, on working days, in the morning and afternoon shifts, being subsequently recorded in the daily pharmaceutical evolutions of each patient (physical and electronic medical records) and available to all members of the multidisciplinary team.

The interventions recorded in the pharmaceutical evolutions were then identified and transferred daily to an electronic spreadsheet in Microsoft Access, developed by the Clinical Pharmacy unit of HU-UFMA, which records and classifies medication errors (MEs) according to what was described by Otero, ${ }^{9}$ a retrofit of the work published in 1998 by the National Coordinating Council for Medication Error Reporting and Prevention, ${ }^{10}$ being classified as inadequate pharmaceutical presentation, wrong dose, wrong treatment duration, administration error, scheduling error, prescription error, incorrect pharmaceutical form, intravenous incompatibility, potential interaction, incorrect medication, 
Figure 1: Flowchart of the clinical activities carried out daily by pharmacists in UCICA/HU-UFMA.

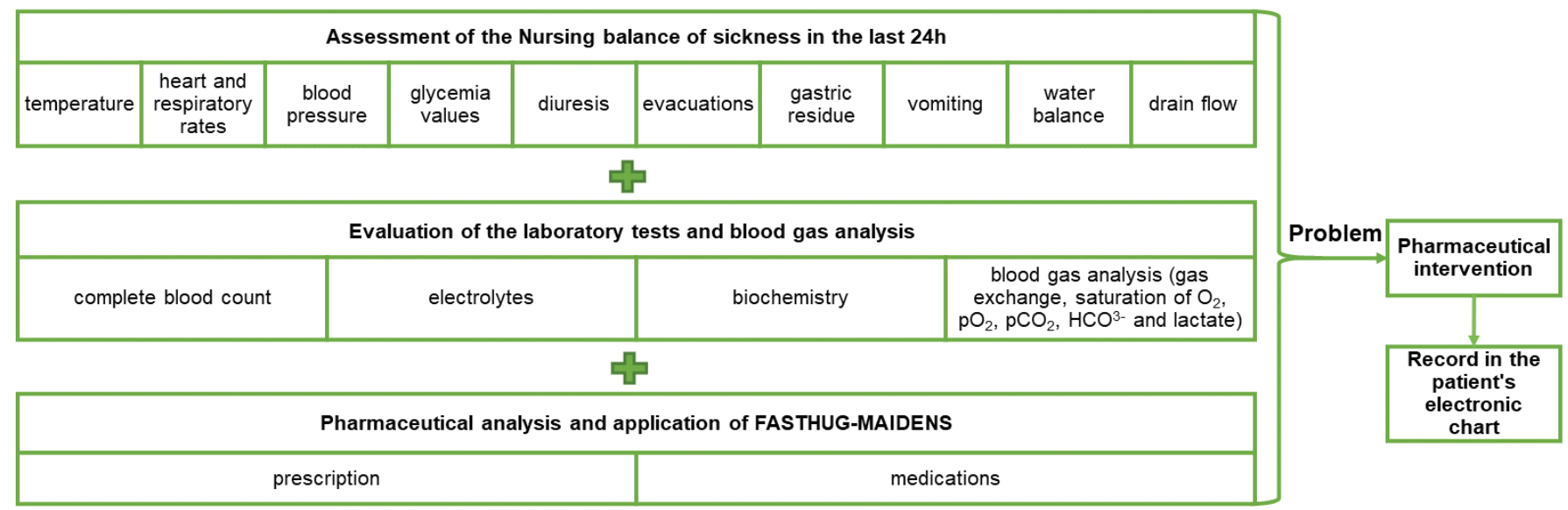

insufficient treatment monitoring, dose or medication omission, reconstitution and dilution prescription absent or inadequate, incorrect or absent administration time and speed. The outcomes of the pharmaceutical interventions were classified according to Hepler \& Strand, ${ }^{11}$ being categorized into curing illness, stopping or slowing down the disease process, eliminating or reducing symptoms, preventing an event, and preventing a disease or symptom. The interventions that aimed at increasing the effectiveness of pharmacotherapy were considered to have a clinical impact, those that prevented adverse drug events (ADEs) were considered preventive, and the interventions that directly reduced the cost associated with the medications were classified as having an economic impact. The sociodemographic variables were obtained from EPIMED reports referring to the months of the research (August to November 2019), those of interest being the following: gender, age, length and type of hospitalization, being classified into two types, surgical (patients in immediate postoperative period) and clinical (patients from the wards) The pharmaceutical interventions recorded in medical records were categorized as accepted, not accepted with reason and not accepted without reason, being subsequently grouped to identify the percentage of acceptance of pharmaceutical interventions by the multidisciplinary team. All the data obtained from the research were analyzed in Microsoft Excel ${ }^{\circ}$ and the absolute and relative frequency statistical tests were carried out, as well as calculations of arithmetic means and standard deviations.

To assess the impact of applying the mnemonic FASTHUG-MAIDENS on the pharmaceutical interventions, secondary data from the clinical pharmacy service of UCICA/HU-UFMA, obtained in the period prior to application (April to July 2019) were used. There were no changes in the type of prescription (electronic), of the pharmaceutical and medical team from UCIC/HU-UFMA before and during the research. The UCICA/HU-UFMA medical team consisted of a fixed intensive medical diarist in the morning, fixed medical on-call staff and medical residents who rotated monthly in the areas of clinical medicine, general surgery, anesthesiology, cardiothoracic surgery, gynecology and obstetrics. This research was submitted to the Research Ethics Committee (Comitê de Ética em Pesquisa, CEP) of HU-UFMA for its appreciation, and was approved under opinion No. $3,462,857$.

\section{Results}

From August to November 2019, 221 were admitted at UCICA/ HU-UFMA; of this total, 166 were surgical patients (75.1\%) and 55 , clinical (24.8\%), with a mean age of 52.1 years old (SD 18.77), 126 being female (57\%) and 95 , male (43\%). The length of stay in the unit was 4.89 days (SD 6.62). Of the total number of patients admitted during the research period, 155 (70.1\%) were followed-up by clinical pharmacists, with the conduction of 1,145 pharmaceutical interventions related to the pharmacotherapy review, FASTHUG-MAIDENS and pharmaceutical analysis of the prescription.

The main information related to the sociodemographic data, type of hospitalization, MEs, pharmaceutical interventions, therapeutic class involved, and objectives of the pharmaceutical interventions are detailed in Table 1. Among the 1,145 pharmaceutical interventions performed, the main ones were inclusion of medications (25.2\%), exclusion of medications (18\%), dose adjustment (12.2\%), incorrect treatment duration (10.9\%) and incorrect or absent administration speed (10.2\%). A total of 1,119 MEs were found among the total interventions; the main ones were medication omission $(24.3 \%)$, wrong dose (12.5\%) and drug incompatibility (11.4\%). The therapeutic class with the highest number of pharmaceutical interventions was that of the antimicrobials, with emphasis on interventions to include reconstitution of lyophilized powder $(41 ; 100 \%)$, adequacy of infusion rate $(53 ; 63.1 \%)$ and adequacy of dilution $(45 ; 67.1 \%)$. Electrolytes were the second therapeutic class with the highest number of interventions, requiring inclusion of therapy (120; $41.5 \%)$, exclusion of therapy $(43 ; 20.9 \%)$ and adjustment of the infusion rate $(8 ; 26.7 \%)$. The main objectives of the pharmaceutical interventions carried out were preventing an event $(55.5 \%)$, controlling the disease process $(14.7 \%)$ and preventing a disease (13\%).

The distribution of the pharmaceutical interventions carried out according to FASTHUG-MAIDENS, the clinical outcomes and the accepted and unaccepted interventions are described in Table 2. Applying the FASTHUG-MAIDENS mnemonic, 860 pharmaceutical interventions were carried out, the main ones being the identification of drug interactions and incompatibilities (18.8\%), evaluation of laboratory tests with indication of initiation, maintenance or interruption of electrolyte replacement (18.7\%), 
Table 1. Main pharmaceutical interventions, medication errors, related therapeutic classes, and sociodemographic data of the patients during the period from August to November 2019 in UCICA/HU-UFMA.

\begin{tabular}{|c|c|}
\hline Information & Descriptive statistics \\
\hline Sociodemographic & $N=221$ \\
\hline Age (years old) - Mean (SD) & $52.1(18.8)$ \\
\hline Female gender - $\mathrm{n}(\%)$ & $126(57.0)$ \\
\hline Male gender - n (\%) & $95(43.0)$ \\
\hline Hospitalization & $\mathrm{N}=221(100.0)$ \\
\hline Length (days) - Mean (SD) & $4.9(6.6)$ \\
\hline \multicolumn{2}{|l|}{ Type of hospitalization - n (\%) } \\
\hline Surgical patient & $166(75.1)$ \\
\hline Clinical patient & $55(24.9)$ \\
\hline Medication errors $\mathrm{n}(\%)$ & $N=1,119(100.0)$ \\
\hline Omission of medication & $278(24.8)$ \\
\hline Incorrect dose & $140(12.5)$ \\
\hline Drug incompatibility & $130(11.6)$ \\
\hline Incorrect treatment duration & 122 (10.9) \\
\hline Incorrect/Absent administration speed & $114(10.2)$ \\
\hline Incorrect medication & $80(7.2)$ \\
\hline Inadequate reconstitution and/or dilution & $71(6.3)$ \\
\hline Reconstitution and/or dilution absent & $64(5.7)$ \\
\hline Insufficient treatment monitoring & $49(4.4)$ \\
\hline Potential interaction & $38(3.4)$ \\
\hline Others & $33(3,0)$ \\
\hline Main pharmaceutical interventions and related therapeutic classes $n(\%)$ & $N=1,145(100.0)$ \\
\hline Inclusion of medication & $289(25.2)$ \\
\hline Electrolytes & $120(41.5)$ \\
\hline Antimicrobials & $27(9.3)$ \\
\hline Heparins & $21(7.2)$ \\
\hline Exclusion of medication & $206(18.0)$ \\
\hline Electrolytes & $43(20.9)$ \\
\hline Antimicrobials & $40(19.4)$ \\
\hline Dose adjustment & $140(12.2)$ \\
\hline Antimicrobials & $54(38.6)$ \\
\hline Antiulcerous & $29(20.7)$ \\
\hline Scheduling guidance & $131(11.5)$ \\
\hline Antiepileptics & $29(22.1)$ \\
\hline Diuretics & $23(17.5)$ \\
\hline Inclusion of infusion speed & $84(7.3)$ \\
\hline Antimicrobials & $53(63.1)$ \\
\hline Opioids & $11(13.1)$ \\
\hline Adequacy of the dilution & $67(5.8)$ \\
\hline Antimicrobials & $45(67.1)$ \\
\hline Corticosteroids & $3(4.5)$ \\
\hline Inclusion of reconstitution & $41(3.6)$ \\
\hline Antimicrobials & $41(100)$ \\
\hline Request for cultures & $40(3.5)$ \\
\hline Blood cultures & $25(62.5)$ \\
\hline Tracheal secretion & $11(27.5)$ \\
\hline Monitoring of drug interaction & $32(2.8)$ \\
\hline Prokinetics & $9(28.1)$ \\
\hline Antimicrobials & $5(15.6)$ \\
\hline Adequacy of the infusion speed & $30(2.6)$ \\
\hline Antimicrobials & $21(70.0)$ \\
\hline Electrolytes & $8(26.7)$ \\
\hline Others & $85(7.5)$ \\
\hline Objective n (\%) & $1,145(100.0)$ \\
\hline To prevent the event & $635(55.5)$ \\
\hline To stop or delay the disease process (control) & $169(14.7)$ \\
\hline To prevent a disease or a symptom & $148(13.0)$ \\
\hline To eliminate or reduce the symptomatology & $102(8.9)$ \\
\hline To cure the disease & $91(7.9)$ \\
\hline
\end{tabular}


Table 2. Distribution, impact and acceptance rate of the pharmacological interventions according to FASTHUG-MAIDENS during the period from August to November 2019 in UCICA/HU-UFMA.

\begin{tabular}{|c|c|c|c|c|c|c|c|}
\hline & \multirow{2}{*}{ Pharmaceutical interventions - mnemonic } & \multirow{2}{*}{$\begin{array}{l}\text { All } \\
N=860 \\
n(\%)\end{array}$} & \multicolumn{3}{|c|}{$\begin{array}{l}\text { Outcome } n(\%) \\
N=1,145\end{array}$} & \multicolumn{2}{|c|}{$\begin{array}{l}\text { Intervention } \mathrm{n}(\%) \\
\mathrm{N}=1,145\end{array}$} \\
\hline & & & $\begin{array}{l}\text { Preventive } \\
\mathrm{N}=1,138\end{array}$ & $\begin{array}{l}\text { Clinical } \\
N=1,110\end{array}$ & $\begin{array}{l}\text { Cost reduction } \\
\mathrm{N}=248\end{array}$ & $\begin{array}{l}\text { Accepted } \\
\mathrm{N}=1,137\end{array}$ & $\begin{array}{l}\text { Not accepted } \\
\mathrm{N}=8\end{array}$ \\
\hline $\mathbf{F}$ & Feeding & $23(2.7)$ & $23(2.0)$ & $23(2.0)$ & - & $23(2.0)$ & - \\
\hline A & Analgesia & $16(2.1)$ & $16(1.4)$ & $16(1.4)$ & - & $16(1.4)$ & - \\
\hline $\mathbf{S}$ & Sedation & $8(0.9)$ & $8(0.7)$ & $8(0.7)$ & - & $8(0.7)$ & - \\
\hline $\mathbf{T}$ & Thromboembolic prophylaxis & $32(3.7)$ & $32(2.8)$ & $32(2.8)$ & $9(3.6)$ & $32(2.8)$ & - \\
\hline H & Hypoactive/Hyperactive delirium & $8(0.9)$ & $8(0.7)$ & $8(0.7)$ & - & $8(0.7)$ & - \\
\hline u & Stress ulcer prophylaxis & $10(1.2)$ & $10(0.8)$ & $10(0.9)$ & $6(2.4)$ & $10(0.8)$ & - \\
\hline $\mathbf{G}$ & Glucose control & $17(2.0)$ & $17(1.5)$ & $17(1.5)$ & - & $17(1.5)$ & - \\
\hline M & Medication reconciliation & $30(3.5)$ & $30(2.6)$ & $30(2.7)$ & - & $30(2.6)$ & - \\
\hline A & Antimicrobials & $103(12.0)$ & $103(9.0)$ & $103(9.3)$ & $40(17.0)$ & $103(9.0)$ & - \\
\hline 1 & Indication of the medications & $100(11.6)$ & $100(8.8)$ & $100(9.0)$ & $48(19.3)$ & $100(8.8)$ & - \\
\hline D & Dose of the medications & $140(16.27)$ & $140(12.3)$ & $140(12.6)$ & $46(18.5)$ & $140(12.3)$ & - \\
\hline $\mathbf{E}$ & $\begin{array}{l}\text { Electrolytes, hematology and other } \\
\text { laboratory tests }\end{array}$ & $161(18.7)$ & $161(14.1)$ & $161(14.5)$ & $43(17.3)$ & $161(14.1)$ & - \\
\hline $\mathbf{N}$ & $\begin{array}{l}\text { No drug interactions, allergies, duplicities or } \\
\text { adverse reactions }\end{array}$ & $162(18.8)$ & $157(13.8)$ & $129(11.6)$ & $6(2.4)$ & $154(13.5)$ & $8(0.6)$ \\
\hline$S$ & Stop dates & $50(5.81)$ & $50(4.4)$ & $50(4.5)$ & $50(20.1)$ & $50(4.4)$ & - \\
\hline
\end{tabular}

dose adjustment $(16.2 \%)$, interventions related to the use of antimicrobials (12\%) and indication of medications (11.6\%). The main outcomes of the interventions were clinical (96.9\%), preventive (99.3\%) and cost reduction (21.6\%), with an acceptance rate of $99.3 \%$ by the multidisciplinary team. Eight pharmaceutical interventions with the suggestion of drug suspension, due to contraindicated drug interactions, were not accepted by the multidisciplinary team, although clinical and laboratory signs of the patients were monitored that showed possible clinical manifestations of drug interactions.

The total number of pharmaceutical interventions carried out from April to June, the period prior to the research, was 560 interventions. Considering the interventions from August to November, the period after the research, the total interventions were 1,145 , resulting in a $104.4 \%$ increase of pharmaceutical interventions after the daily application of FASTHUG-MAIDENS.

\section{Discussion}

The application of the FASTHUG-MAIDENS mnemonic increased by $104.4 \%$ the number of interventions performed during the research, ratifying the importance of the application of this mnemonic by clinical pharmacists in critically-ill patients. The increase in the number of pharmaceutical interventions after applying the mnemonic is similar to studies that show that daily interventions from a checklist improve several care processes, which can reduce mortality and length of stay in critically-ill patients. ${ }^{12}$

The main therapeutic class in need of pharmaceutical intervention was that of the antimicrobials (364), of which the following stand out: adjustment of sub-therapeutic dose (11.2\%), supratherapeutic (3.5\%), beginning, choice, escalation or de-escalation as institutional protocols, infection site and antimicrobial sensitivity test (12.9\%), incorrect treatment duration (10.9\%), adjustment of infusion time $(17.8 \%)$, drug interactions $(1.3 \%)$, drug incompatibilities (10.1\%), dilution and reconstitution adjustments $(27.4 \%)$. In addition to that, 40 culture collections were suggested in patients using antibiotic therapy considering sepsis management protocols and pharmacotherapy monitoring. The importance of these interventions related to the antimicrobial therapy is reinforced by a multicenter study that demonstrated that there is a reduction in the consumption of antibiotics when all prescriptions were reviewed by pharmacists, in addition to when pharmacists acted as antibiotic consultants, highlighting that pharmaceutical interventions have a positive impact in reducing the consumption of antibiotics and that they must be supported..$^{13}$ In addition to that, clinical pharmacists play a key role in antimicrobial stewardship, providing impacts on reducing prescription and consumption of antibiotics, reducing the proportion of surgical prophylaxis and increasing the rational use of antimicrobials. ${ }^{14}$ In addition, the review and intervention in the microbiology results by the clinical pharmacist positively impact on the treatment of patients, reducing treatment failure rates when interventions are accepted. ${ }^{15}$ Our research reinforces that the interventions by clinical pharmacists assist the multidisciplinary team in the optimization of antimicrobial therapy, promoting its rational use.

A total of 140 drug dose adjustments were made, the main ones being antimicrobials $(38.6 \%)$, antiulcerous $(20.7 \%)$, electrolyte solutions (6.4\%), corticosteroids (5\%), analgesics (4.2\%), opioids $(4.2 \%)$ and others (20.7\%). Considering that the antimicrobials were the pharmacological class with the highest number of interventions for dose adjustment, especially sub-therapeutic (29.2\%), the impact of these interventions is of utmost importance to define better clinical outcomes in the treatment of infections, in addition to having a direct impact on the reduction of antimicrobial resistance by the microorganisms.

The evaluation of laboratory tests is routine in the daily care of critically-ill patients. Pharmacists must monitor patients in laboratory for adverse drug events (ADEs) that alter electrolytes, hematimetry or other laboratory values, suggesting treatment alternatives with the multidisciplinary team. ${ }^{6}$ In addition to that, the pharmacist can recommend starting or discontinuing 
replacement of electrolytes, nutrients, minerals, blood and liquid products, if appropriate..$^{5}$ During the research, 161 interventions (18.2\%) were performed related to the prescription of electrolytes (potassium, magnesium, calcium, sodium and phosphorus), especially regarding initiation (73\%), interruption $(26.7 \%)$ and dose guidance $(5.6 \%)$, in addition to dilution and infusion rate guidelines. Most electrolytes (potassium chloride, magnesium sulfate and potassium phosphate) are considered potentially dangerous medications (PDMs); these are more likely to cause significant harms to the patients due to failure in the use process. ${ }^{16}$ The research shows the importance of the pharmacist in the management of PDMs, being reinforced by studies that demonstrate that the participation of pharmacists are fundamental in the safety and use of PDMs, since they are professionals able to identify and prevent risks related to concentration, physicalchemical compatibility, drug interactions, dose, pharmaceutical form, administration route and times, ${ }^{17}$, in addition to the daily clinical assessment of the need to initiate, maintain or interrupt electrolyte replacement. ${ }^{5}$

The interventions performed with indication or interruption of drug therapy were related to laxatives (18\%), prokinetics (17\%), analgesics $(12 \%)$, antiemetics $(10 \%)$, antihypertensives $(9 \%)$, vitamins $(9 \%)$ and corticosteroids (6\%). 50 interruptions of therapeutic regimens were performed for a longer duration of treatment, mainly with antimicrobials (74\%), corticosteroids (12\%), albumin (7\%) and dexmedetomidine $(5 \%)$, ensuring rational use, cost reduction and less consumption of medications, especially antimicrobials. These data reinforce that health institutions must use clinical pharmacists as a vital component in a process improvement strategy and in promoting an ideal pharmacotherapy. ${ }^{18}$

In twenty-two patients, 32 serious drug interactions were identified, of which $59.3 \%$ were related to the risk of QT prolongation. The main conduct related to this interaction was the intensification of cardiological monitoring, in addition to assessing the risk-benefit of maintaining the related medications. However, four patients evolved with arrhythmia and had medication withdrawals that prolonged the QT interval (domperidone and haloperidol). Two patients had omeprazole replaced by ranitidine due to drug interaction with tacrolimus, evidenced by increased serum tacrolimus levels and risk of toxicity in transplanted patients. The other drug interactions identified resulted in an increased risk of nephrotoxicity, serotonin syndrome, myopathy, rhabdomyolysis and paralytic ileus. The rate of potential drug interactions identified in the sample was $14.1 \%$, similar to that found (18\%) in other studies. ${ }^{19}$ The main therapeutic classes involved with potential drug interactions were antimicrobials (37.9\%), prokinetics $(31 \%)$, antidepressants $(17.2 \%)$, sedatives (10.3\%) and antiepileptics (6.8\%). In another study, sedatives, antithrombotic, antifungal or antibiotic agents (macrolides, fluoroquinolones and cotrimoxazole) are responsible for $75 \%$ of the main drug interactions found in intensive care, and the identification of these interactions in intensive care practice is a complex task. ${ }^{19}$ Considering the large number of drug interactions in intensive care, due to polypharmacy, intensive care pharmacists reduce the prevalence of drug interactions, providing the intensivists, according to specific situations of each patient, only relevant information on potential drug interactions. ${ }^{20,21,22}$

Drug incompatibilities are physical-chemical reactions that occur in vitro between two or more drugs, when the solutions are combined in the same syringe, equipment or vial. ${ }^{11}$ The physical reactions can cause visible changes, such as precipitation, color change, consistency, opalescence or gas production. ${ }^{23} \mathrm{~A}$ total of 129 drug incompatibilities were identified in the prescriptions of 33 patients, representing $21.2 \%$ of the population. The main classes of related medications were diuretics, anticonvulsants, antimicrobials, corticosteroids and electrolyte solutions. The interventions carried out to manage drug incompatibilities were guidance on the scheduling of injectable medications, washing of access and interruption of infusions, when possible, with the Nursing team, in addition to adjusting the infusion time of these medications.

Medication reconciliation in intensive care is among the interventions that reduce medication errors. ${ }^{24}$ Bell et al. states that discharge from the ICU is a time when long-term treatment goals must be met and the usual medications must be restarted or reconsidered since, due to the critical condition of the patients at admission, medications for continuous use can be suspended temporarily. ${ }^{25}$ Focus on post-ICU care is needed to reduce inappropriate drug discontinuation and unintended continuation of medications prescribed in the ICU after a serious illness. ${ }^{26}$ Thirty interventions were conducted in relation to drug reconciliation, especially regarding inclusion (30\%) and suspension of antihypertensive drugs (23.3\%), suspension of oral hypoglycemic agents (16.6\%) and suspension of anxiolytics, antidepressants and antipsychotics (30\%) due to the lower level of consciousness.

32 interventions were performed regarding the prophylaxis of venous thromboembolism (VTE), especially regarding the request for initiation (65.6\%) and suspension (34.3\%) of pharmacological prophylaxis. The $8^{\text {th }}$ Cosensus of the American College of Chest Physicians (ACCP) on prevention of VTE points out that the vast majority of hospitalized patients have at least one risk factor for the development of VTE, and nearly $40 \%$ have three or more, and points out that thromboprophylaxis is the initial strategy to improve the safety of hospitalized patients. ${ }^{27}$ Farhat et al. highlights the need for the evaluation of high-risk clinical and moderate-risk surgical patients, since only $54 \%$ and $4 \%$ of these patients, respectively, received appropriate chemoprophylaxis, with the need to improve patient safety in relation to VTE in the first few hours of hospitalization. ${ }^{28}$ Our results reinforce that the clinical pharmacist has the technical capacity to assess risk factors to suggest the initiation or suspension of pharmacological therapy for thromboprophylaxis, providing safety to the patients, especially considering that heparins are classified as PDMs.

23 interventions related to food were conducted, of which six (26\%) were requests for a suspension in the diet to administer medications, due to the interaction of the enteral diet with medications (phenytoin and levothyroxine). The other interventions were the inclusion of a hypertonic glucose solution in fasting patients (21.7\%) and inclusion of intravenous vitamin supplementation in patients on parenteral nutrition (52.2\%).

In view of the data found and considering the importance of the multidisciplinary team in the care of critically-ill patients, the clinical pharmacist has the technical capacity to assist intensive care physicians in the safe prescription of medications, providing essential information such as reconstitution, dilution, infusion time, dose, dosage, administration route, drug interactions and incompatibilities, in addition to clinical follow-up of patients, especially acting in the management of antimicrobials, PDMs and optimization of pharmacotherapy. The application of the FASTHUG-MAIDENS tool was effective in increasing the number of pharmaceutical interventions in intensive care, providing greater safety in care for critically-ill patients. A recent systematic 
review by Lee et al. on the role of the pharmacist in intensive care showed a significant reduction in mortality, length of stay in the ICU and the number of preventable and non-preventable events, highlighting the importance of pharmaceutical care in improving the clinical outcomes in critically-ill patients. ${ }^{29}$

Among the limitations of the work is the study design, which makes it impossible to establish the causality between the medication errors found and possible clinical outcomes, in addition to the failure to measure the possible clinical outcomes resulting from the pharmaceutical interventions, requiring the association of this study with others for obtaining more robust results on the application of the FASTHUG-MAIDENS mnemonic by intensive care pharmacists.

\section{Conclusion}

The increase in the number of pharmaceutical interventions performed, compared to the total interventions conducted prior to the research, demonstrates the effectiveness of the application of the FASTHUG-MAIDENS mnemonic by intensive care pharmacists in the optimization of pharmacotherapy for critically-ill patients.

\section{Funding sources}

None.

\section{Collaborators}

IML, IAN, SBV, NML, DAC, ACJ ad LMV: conception and design or data analysis and interpretation. IML, IAN and EJS: writing of the article or relevant critical review of the intellectual content.

\section{Acknowledgments}

To the teams from the Clinical Pharmacy Units, Intensive Care Units for Adults and the UFMA University Hospital for allowing this research to be conducted.

\section{Conflicts of interest statement}

The authors declare that there are no conflicts of interest in relation to this article.

\section{References}

1. BRASIL. Conselho Federal de Farmácia (CFF). Resolução no 585, de 29 de agosto de 2013. Regulamenta as atribuições clínicas do farmacêutico e dá outras providências. Diário Oficial da União, 25 set 2013. Seção 1, p. 186.

2. Preslaski CR, Lat I, MacLaren R et al. Pharmacist Contributions as Members of the Multidisciplinary ICU Team. CHEST. 2013; 144(5):1687-1695.

3. BRASIL. Conselho Federal de Farmácia (CFF). Resolução $n^{\circ}$ 675, de 31 de Outubro de 2019. Regulamenta as atribuições do farmacêutico clínico em unidades de terapia intensiva e dá outras providências. Diário Oficial da União, 21 nov 2019.
Seção 1, p. 128.

4. Richter A, Bates I, Thacker M et al. Impact of the introduction of a specialist critical care pharmacist on the level of pharmaceutical care provided to the critical care unit. Int J PharmPract. 2016; 24(4):253-261.

5. Vincent HM, Douglas LM, Weatherby EM, et al. A Standardized, Structured Approach to Identifying Drug-Related Problems in the Intensive Care Unit: FASTHUG-MAIDENS. Can J HospPharm. 2011; 64(5):366-369.

6. Vincent, JL. Give your patient a fast hug (at least) once a day. CritCare Med. 2005; 33(6):1225-1229.

7. Masson SC, Mabasa VH, Malyuk DL et al. Evidence for FASTHUG-MAIDENS, a Mnemonic for Identifying Drug-Related Problems in the Intensive Care Unit. Can J HospPharm. 2013; 66(3):157-162.

8. Flannery $\mathrm{AH}$, Pandya $\mathrm{K}$, Laine ME et al. Managing the Rising Costs and High Drug Expenditures in Critical Care Pharmacy Practice. Pharmacotherapy. 2017;37(1):54-64.

9. Otero LMJ, Castaño RB, Pérez EM et al. Actualización de la calssificación de errores de medicación del grupo Ruiz-Jarabo. Farm. General 2000; 32(1):38-52.

10. National Coordinating Council for Medication Error Reporting and Prevention. Taxonomy of medication errors - 1998-1999 [online]. [cited 2019 Nov 20]. Available from: https://www. nccmerp.org/about-medication-errors

11. Heppler CD, Strand LM. Opportunities and responsibilities in pharmaceutical care. Am J Hosp Pharm. 1990;47(3):533-543.

12. Weiss $\mathrm{CH}$, Moazed F, McEvoy CA, et al. Prompting physicians to address a daily checklist and process of care and clinical outcomes: a single-site study. Am J Respir Crit Care Med. 2011;184(6):680-686.

13. Ourghanlian C, Lapidus N, Antignac M, et al. Pharmacists' role in Antimicrobial Stewardship and relationship with antibiotic consumption in hospitals: an observational multicentre study. J Glob Antimicrob Resist. 2019;20:131-134.

14. Wang $H$, Wang $H, Y u X$, et al. Impact of antimicrobial stewardship managed by clinical pharmacists on antibiotic use and drug resistance in a Chinese hospital, 20102016: a retrospective observational study. BMJ Open. 2019;9:e026072.

15. Wattengel BA, Sellick JA, Mergenhagen KA. Outpatient antimicrobial stewardship: Optimizing patient care via pharmacist led microbiology review. Am J Infect Control. 2019;1-5.

16. Sullivan KM, Le PL, Ditoro MJ, et al. Enhancing high alert medication knowledge among pharmacy, nursing, and medical staff. J Patient Saf. 2013;0(0):1-5.

17. Mayimele N, Meyer JC, Schellack N. What role does the pharmacist play in medicine management at ward level? SA Pharm J. 2015; 82(1):37-42.

18. Buckley MS, Knutson KD, Agarwal SK, et al. Clinical Pharmacist-Led Impact on Inappropriate Albumin Use and Costs in the Critically III. Ann Pharmacother. 2020;54(2):105-112.

19. Vanham D, Spinewine A, Hantson P et al. Drug-drug interactions in the intensive care unit: Do they really matter?. J Crit 
Care. 2017;38:97-103.

20. Bertsche T, Pfaff J, Schiller P et al. Prevention of adverse drug reactions in intensive care patients by personal intervention based on an electronic clinical decision support system. Intensive care medicine. 2010;36(4):665-672.

21. Hasan SS, Lim KN, Anwar M et al. Impact of pharmacists' intervention on identification and management of drug-drug interactions in an intensive care setting. Singapore medical journal. 2012;53(8):526-531.

22. Rivkin A, Yin H. Evaluation of the role of the critical care pharmacist in identifying and avoiding or minimizing significant drug-drug interactions in medical intensive care patients. Journal of critical care. 2011;26(1):104.e1-104.e6.

23. Trissel LA. Handbook on injectable drugs. 17th ed. Maryland: American Society of Health- System Pharmacists. 2013.

24. Manias E, Williams A, Liew D. Interventions to reduce medication errors in adult intensive care: a systematic review. $\mathrm{Br} J$ Clin Pharmacol. 2012;74:411-423.

25. Bell CM, Brener SS, Gunraj N et al. Association of ICU or hospital admission with unintentional discontinuation of medications for chronic diseases. JAMA. 2011;306:840-847.

26. Liesbeth BEB, Nicole GMH, Rogier AMQ et al. The effect of a medication reconciliation program in two intensive care units in the Netherlands: a prospective intervention study with a before and after design. Ann Intensive Care. 2018;8(1):19.

27. Geerts WH, Bergqvist D, Pineo GF et al. Prevention of venous thromboembolism. American College of Chest Physicians Evidence-Based Clinical Practice Guidelines (8th ediiton). Chest. 2008;133(6):381S-453S.

28. Farhat FCLG, Gregório HCT, Carvalho, RDP. Evaluation of deep vein thrombosis prophylaxis in a general hospital. J Vasc Bras. 2018;17(3):184-192.

29. Lee H, Ryu K, Sohn Y et al. Impact on Patient Outcomes of Pharmacist Participation in Multidisciplinary Critical Care Teams: A Systematic Review and Meta-Analysis. CritCare Med. 2019;47:1243-1250. 